\title{
Erratum to: The Role of Connexin 43 and Hemichannels Correlated with the Astrocytic Death Following Ischemia/ Reperfusion Insult
}

\author{
Xueyu Wang $\cdot$ Aihua Ma $\cdot$ Weiwei Zhu \\ Liping Zhu $\cdot$ Yutian Zhao $\cdot$ Jiashui Xi \\ Xinying Zhang $\cdot$ Bojun Zhao
}

Published online: 29 March 2013

(C) Springer Science+Business Media New York 2013

\section{Erratum to: Cell Mol Neurobiol (2013) 33:401-410 \\ DOI 10.1007/s10571-013-9906-y}

The original publication of this manuscript contained an incorrect author list. David L. Becker should not appear as an author of this paper. The author list appears correctly above. A revised Acknowledgements section also appears below.
Acknowledgments The technical assistance of Mr. Tim Robson in study (Department of Cell and Developmental Biology, UCL) is gratefully acknowledged. This work was supported by Shandong Natural Foundation, China to Prof. A. Ma.

The online version of the original article can be found under doi:10.1007/s10571-013-9906-y.

X. Wang · A. Ma (凹) - L. Zhu · J. Xi · X. Zhang $\cdot$ B. Zhao

Division of Neurology, Department of Pediatrics,

Provincial Hospital Affiliated to Shandong University,

324 Jingwu Road, Jinan 250021, China

e-mail: aihuama@hotmail.co.uk

W. Zhu

Department of Pediatrics, Central Hospital of Jinan Affiliated

to Shandong University, Jinan, China

Y. Zhao

School of Pharmacy, Cardiff University, Cardiff, UK 